\title{
GIÁO DỤC SỨC KHỎE SINH SẢN CHO TRẺ VỊ THÀNH NIÊN Ở CÁC TRƯỜNG TRUNG HOC CƠ SỞ TRÊN ĐIA BÀN TİNH THỪ'A THIÊN HUẾ: KHẢO SÁT KIẾN THỨC, THÁI Độ, THỰC HÀNH CỦA CHA ME HỌC SINH
}

\author{
Ngô Thị Hồng Uyên ${ }^{1}$, Nguyễn Hoàng Phúc ${ }^{2}$, \\ Lê Nguyễn Quỳnh Như², Võ Tống Khánh Quân², Bùi Thanh Dương², \\ Huỳnh Thị Kim Sướngen , Trần Thị Thùy Trang ${ }^{2}$, Nguyễn Minh Tú ${ }^{2}$, \\ Lê Thị Phương Thuận ${ }^{2}$, Hoàng Hữu Hải ${ }^{2}$, Trần Đình Trung ${ }^{1}$
}

\section{TÓM TẮT}

Nghiên cứu được thực hiên tai 4 trường THCS trên địa bàn tỉnh Thửa Thiên Huế nằm 2020 để đánh giá kiến thức, thái độ, thực hành về giáo dục sức khỏe sinh sản cho trẻ vị thành niên (VTN) của cha me học sinh. Thiết kế nghiên cứu mô tả cắt ngang với 422 người tham gia, phỏng vấn tại hộ gia đình. Kết quả cho thấy: có $58,1 \%$ cha me có kiến thức đat, $52,8 \%$ cha me có thái độ đạt và $51,7 \%$ cha me có thực hành đạt về vấn đề giáo dục sức khỏe sinh sản trẻ viTN. Kết quả cho thấy, kiến thức, thái độ, thực hành của cha me học sinh về giáo dục sức khỏe sinh sản cho trẻ VTNN chưa cao. Cha me cần quan tâm nhiều hơn đến vấn đề thay đổi cơ thể, tâm lý tuổi mới lớn của trẻ , các biện pháp phòng tránh thai và một số bệnh nhiếm khuẩn đường sinh sản.

Tư khóa: Sức khỏe sinh sản, vị thành niên, cha me học sinh.

\section{SUMMARY}

\section{SEXUAL REPRODUCTIVE HEALTH} EDUCATION (SRHE) TOWARDS ADOLESCENCES IN SECONDARY HIGH SCHOOL IN THUA THIEN HUE PROVINCE: A SURVEY OF KNOWLEDGE, ATTITUDE, PRACTISE AMONG THEIR PARENTS

The study is conducted in 4 secondary high schools in Thua Thien Hue province in 2020 to evaluate the knowledge, attitude, practise of parents about sexual reproductive health education to their children. The descriptive cross-sectional study has 422 participants, do household interview. The results show that: the prevalence of having adequate knowledge about SRHE is $58.1 \%$, the prevalence of having appropriate attitude towards SRHE is $52.8 \%$ and the prevalence of practising SRHE towards their children is $51.7 \%$. The results suggest that knowledge, attitude, practise of parents about SRHE to their children remain limitations. Parents need to give more intentions towards physical and metal changes, contraception, and STDs among adolescences.

\footnotetext{
${ }^{1}$ Trường Đại học Kỹ thuật $Y$ - Dược Đà Nẵng

${ }^{2}$ Trường Đại học $Y$ - Dược, Đại học Huế.

Chiu trách nhiệm chính: Trần Đình Trung

Email: trandinhtrung@dhktyduocdn.edu.vn

Ngày nhận bài: 15.9.2021

Ngày phản biện khoa học: 12.11.2021

Ngày duyệt bài: 22.11.2021
}

Keywords: Sexual reproductive health, adolescence, parents.

\section{I. ĐĂT VẤN ĐỀ}

Sức khoẻ sinh sản (SKSS), sức khoẻ tình dục là cân thiết cho bất kì sự phát triển bền vững nào bởi mối quan hệ chặt chẽ của nó đến bình đẳng giới và sự khoẻ mạnh toàn diện. Bởi những tác động lâu dài mà những vấn đề này để lại: có thai ngoài ý muốn, những khó khăn khi mang thai, bạo lực giới, và những bệnh lây nhiễm qua đường tình dục vẫn còn là mỗi đe doạ lên sức khoẻ của cả hai giới và gia đình [5].

Một đánh giá về kiến thức SKSS và tình dục tại Lào cho thấy trẻ vị thành niên (VTN) sống ở khu vực nông thôn có kiến thức về SKSS và tình dục thấp hơn với khu vực thành phố [4]. Trong khi đó, gia đình và bố mẹ là yếu tố đóng vai trò quan trọng trong sự phát triển của trẻ VTN [7] [3]. Tuy nhiên, thách thức lớn trong việc giáo dục con cái của phụ huynh là vừa phát triển được sự hiểu biết của con cái, vừa ngăn chặn được những hành động thiếu chín chắn của con [3]. Nhiều nghiên cứu trước đây đã chỉ ra vai trò của sự giáo dục từ phụ huynh bảo vệ con cái khỏi nhữ̛ng hành vi tình dục nguy hiểm [7] [3]và nâng cao sự hài lòng về cuộc sống nói chung cho trẻ. Vậy nên kiến thức, thái độ và thực hành giáo dục SKSS cho con cái ở các bậc phụ huynh sẽ là yếu tố then chốt, có thể ảnh hưởng tích cực hoặc tiêu cực đến sự phát triển bình thường về SKSS và tình dục.

Tại Việt Nam, theo Kế hoạch hành động quốc gia về chăm sóc sức khỏe sinh sản, sức khỏe tình duc cho VTN, thanh niên giai đoạn 2020-2025, tuổi trung bình lần quan hệ tình dục đâu tiên của các đối tượng điều tra ở nhóm tuổi 14-24 là 18,7 tuổi (2017). Thanh thiếu niên trong đô tuổi 10-24 có kiến thức cơ bản nhưng không đầy đủ về HIV/AIDS. Chỉ có $21 \%$ nam từ 10-24 tuổi có thể nêu được một triệu chứng của các viêm nhiễm đường sinh sản và tỷ lệ này ở nữ là 19 [1]. Tuy nhiên, những nghiên cứu để đánh giá kiến thức, thái độ và thực hành trên đối tượng là các bậc cha mẹ vẫn còn hạn chế, trong 
khi đó họ là nhóm có thể để lại những tác động lâu dài trên đối tượng là trẻ VTN. Từ những lý do trên, chúng tôi thực hiện đề tài này nằm mô tả kiên thức, thái độ, thực hành về giáo dục SKSS cho trẻ VTN của cha mẹ ở các trường trung học cơ sở.

\section{II. ĐỐI TƯỢNG VÀ PHƯƠNG PHÁP NGHIÊN CỨU} 2.1. Đối tượng nghiên cứu, cỡ mẫu

Đối tượng nghiên cứu: Các bậc cha mẹ của học sinh ở các trường THCS

Tiêu chí chon mấu: Các bậc cha mẹ có con đang theo học tại các trường THCS trên địa bàn tỉnh Thừa Thiên Huế

Tiêu chí loại trừ: Đối tượng từ chối tham gia nghiên cứu, hoặc có bất thường về tâm thần.

\subsection{Thời gian và địa điểm nghiên cứu:}

Thời gian: Nghiên cứu được triển khai từ tháng 05/2020 đến tháng 09/2020.

Địa điểm: Trường THCS Trần Cao Vân, THCS Duy Tân, THCS Nguyễn Chí Diễu và THCS Lê Hồng Phong.

\subsection{Phương pháp nghiên cứu:}

2.3.1. Thiết kế nghiên cứu: Nghiên cứu mô tả cắt ngang

2.3.2. Cỡ mấu và phương pháp chọn mẫu:

Cỡ mẫu: Công thức tính cỡ mẫu

$$
n=\frac{z_{\left(\frac{\alpha}{2}\right)}^{2} \times p(1-p)}{d^{2}}
$$

Trong đó: n: số lượng mẫu nghiên cứu.

$Z$ : Hệ số tin cậy $(Z=1,96$ với độ tin cậy là $95 \%)$, sai số cho phép là $5 \%$.

P: Tỷ lệ bậc cha mẹ có kiến thức đúng về kiến thức, thái độ, thực hành giáo dục sức khỏe sinh sản cho trẻ VTN, lấy $p=0,5$ (vì trong quá trình tìm kiếm tài liệu chưa tìm thấy nghiên cứu tương tự trước đây ở cùng đối tượng nghiên cứu). d: khoảng sai lệch mong đợi (lấy $d=0,05)$.

Thay các giá trị vào công thức trên, ta được $\mathrm{n}$ $=384$. Để dự phòng trong quá trình điều tra phỏng vấn, chúng tôi chọn thêm $10 \%$ so với cõ mẫu, $\mathrm{n}=384+384 \times 10 \%=422$.

Phương pháp chon mấu. Áp dụng phương pháp chọn mấu phân tẩng theo tỷ lệ

Giai đoạn 1: 422 đối tượng nghiền cứu là cha hoặc mẹ của học sinh được chia đều cho 4 trường sau đó chọn mẫu phân tầng tỷ lệ theo tỷ lệ học sinh theo các khối lớp 6 , lớp 7 , lớp 8 và lớp 9.

Giai đoạn 2: Tiến hành chọn mẫu ngấu nhiên đơn theo số lượng học sinh đã được chọn ở mỗi khối lớp cho đến khi đủ chỉ tiêu cõ̃ mẫu đề ra.

\subsubsection{Nội dung nghiên cứu \\ Bộ câu hói gồm 4 phần:}

Phần I. Đặc điểm thông tin chung của đối tượng nghiên cứu gồm có 12 câu hỏi về tuổi, giới tính, tôn giáo, tình trạng hôn nhân, nghề nghiệp, trình độ học vấn, lớp học của con, giới tính của con, trẻ là con thứ mây trong nhà, học lực năm gân nhất và điều kiện kinh tế của gia đình.

Phần II: Kiến thức của cha mẹ học sinh về vấn đề giáo dục sức khỏe sinh sản cho con trẻ VTN gồm có 14 câu hỏi về những kiến thức sức khỏe sinh sản trẻ VTN.

Đánh giá điểm đạt kiến thức của đối tượng nghiên cứu khi có điểm trung bình $\geq 10$ và khồng đạt $<10$

Phần III: Thái độ của cha mẹ học sinh về vấn đề giáo dục sức khỏe sinh sản cho con trẻ VTN gồm có 5 câu hỏi được đánh giá theo thang đo Likert 5 mức độ từ 1 (rất không đồng ý) đến 5 (rất đồng ý).

Quy đổi điểm đạt thái độ khi có trung bình $\geq 22$ và không đạt $<22$

Phần IV: Thực hành của cha me học sinh về vấn đề giáo dục sức khỏe sinh sản cho con trẻ VTN gồm có 11 câu hỏi về mức độ thường xuyên trao đổi với con, thời điểm gần nhất, vấn đề thường trao đổi, khoảng thời gian hay trao đổi, những khó khăn khi trao đổi và lý do tại sao chưa trao đổi với con.

Quy đổi điểm đạt thực hành khi có tổng điểm $\geq 6$ và không đạt $<6$

2.3.4. Phương pháp thu thập thông tịn. Thu thập số liệu sử dụng bộ câu hỏi soạn sẵn (đã được điều tra thứ) để các bậc cha mẹ học sinh tự điền.

2.3.5. Phương pháp xử lý số liệu: Số liệu được nhập liệu bằng phần mềm EpiData 3.1 và được phẩn tích bằng phần mềm SPSS 20.0. Sử dụng tỷ lệ phần trăm, bảng phân phối tần số để mô tả.

2.4. Đạo đức nghiên cứu. Nghiên cứu được sự chấp thuận của cơ sở nghiên cứu. Đối tượng nghiên cứu được giải thích và đồng ý tham gia nghiên cứu. Mọi thông tin liên quan đến đối tượng được mã hóa và nhập máy tính đảm bảo bí mật

\section{KẾT QUẢ NGHIÊN CỨU}

3.1. Đặc điểm chung của đối tượng nghiên cứu $(n=422)$

Bảng 1. Đặc điêm chung của đôî̉ tượng nghiên cứu ( $n=422)$

\begin{tabular}{|c|c|c|}
\hline $\begin{array}{l}\text { Đắc điểm } \\
\text { chung }\end{array}$ & Các yếu tố & 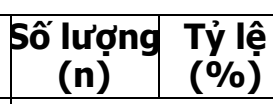 \\
\hline Tuổi & $\begin{array}{c}\text { Tuối trung bình } \\
\pm S D\end{array}$ & $43,05 \pm 5,25$ \\
\hline Giới tính & $\mathrm{Nam}$ & 36,7 \\
\hline
\end{tabular}


VIETNAM MEDICAL JOURNAL N²2 - DECEMBER - 2021

\begin{tabular}{|c|c|c|c|}
\hline & Nữ & 267 & 63,3 \\
\hline Dân tộc & Kinh & 422 & 100 \\
\hline \multirow{3}{*}{ Tôn giáo } & Phật giáo & 229 & 54,3 \\
\hline & Thiên chúa giáo & 26 & 6,2 \\
\hline & Không & 167 & 39,6 \\
\hline \multirow{3}{*}{$\begin{array}{l}\text { Tình trạng } \\
\text { hôn nhân }\end{array}$} & Đang có vợ/chồng & 393 & 93,1 \\
\hline & Ly hôn/ Ly thân & 20 & 4,7 \\
\hline & Góa phụ & 9 & 2,1 \\
\hline \multirow{4}{*}{$\begin{array}{l}\text { Trình độ } \\
\text { học vấn }\end{array}$} & Tiểu học & 16 & 3,8 \\
\hline & Trung học cơ sơ & 73 & 17,3 \\
\hline & $\begin{array}{c}\text { Trung học phố } \\
\text { thông }\end{array}$ & 96 & 22,7 \\
\hline & $\begin{array}{c}\text { Trungcấp/Caođắng/ } \\
\text { ĐH/trênĐH }\end{array}$ & 237 & 56,2 \\
\hline \multirow{5}{*}{$\begin{array}{l}\text { Nghề } \\
\text { nghiệp }\end{array}$} & Cán bộ viên chức & 161 & 38,2 \\
\hline & Buôn bán & 134 & 31,8 \\
\hline & Công nhân & 82 & 19,4 \\
\hline & Nông dân & 5 & 1,2 \\
\hline & Nô̂i trơ & 40 & 9,5 \\
\hline \multirow{2}{*}{$\begin{array}{c}\text { Điều kiện } \\
\text { kinh tế của } \\
\text { gia đình }\end{array}$} & Nghèo, cận nghèo & 13 & 3,1 \\
\hline & Bình thường & 409 & 96,9 \\
\hline \multirow{4}{*}{$\begin{array}{l}\text { Lớp học } \\
\text { của con }\end{array}$} & Lớp 6 & 103 & 24,4 \\
\hline & Lớp 7 & 111 & 26,3 \\
\hline & Lớp 8 & 99 & 23,5 \\
\hline & Lớp 9 & 109 & 25,8 \\
\hline \multirow{2}{*}{$\begin{array}{l}\text { Giới tính } \\
\text { của con }\end{array}$} & Nam & 218 & 51,7 \\
\hline & Nữ & 204 & 48,3 \\
\hline \multirow{2}{*}{\begin{tabular}{|c|} 
Thứ tự của \\
con trong \\
gia đình
\end{tabular}} & Con đầu & 217 & 51,4 \\
\hline & Con thứ 2 trở lên & 205 & 48,6 \\
\hline
\end{tabular}

\begin{tabular}{|c|c|c|c|}
\hline $\begin{array}{c}\text { Kết quả } \\
\text { học tập của } \\
\text { con }\end{array}$ & Giỏi, khá & 393 & 93,1 \\
\cline { 2 - 4 } & Trung bình, yếu & 29 & 6,9 \\
\hline
\end{tabular}

Các bậc cha mẹ tham gia nghiên cứu có độ tuổi trung bình là 43 tuổi, đối tượng nghiên cứu chủ yếu là nữ giới chiếm $63,5 \%$, có $54,3 \%$ đối tượng theo Phật giáo. Có 93,1\% đối tượng đang có vớ/chồng, có $96,9 \%$ đối tượng có kinh tế bình thường. Giới tính của con chủ yếu là nam chiếm $51,7 \%$, các đối tượng nghiên cứu có con chủ yếu là con đầu với $51,4 \%$ và có học lực giỏi, khá chiếm đa số $93,1 \%$.

3.2. Kiến thức, thái độ, thực hành của cha mẹ học sinh về vấn đề giáo dục SKSS trẻ VTN cho con

Bảng 2. Đánh giá kiến thức, thái độ, thức hành của cha me học sinh về vấn đề giáo dục SKSS trẻ VTN

\begin{tabular}{|c|c|c|c|}
\hline & & Số lượng & Tỷ lệ \\
\hline Kiến thức & Đạt & 245 & 58,1 \\
\hline & Chưa đạt & 177 & 41,9 \\
\hline Thái độ & Đạt & 223 & 52,8 \\
\hline & Chưa đạt & 199 & 47,2 \\
\hline Thực hành & Đạt & 218 & 51,7 \\
\hline & Chưa đạt & 204 & 48,3 \\
\hline
\end{tabular}

Kiến thức các đối tượng tham gia nghiên cứu có kiến thức, thái độ, hành vi về vấn đề giáo dục SKSS cho trẻ VTN đều lớn hơn $50 \%$.

3.2. Kiến thức của cha me học sinh vê vấn đề giáo dục sức khỏe sinh sản trẻ VTN cho con $(n=422)$

Bảng 3. Đánh giá kiên thức của đôî tượng nghiên cứu (n=422)

\begin{tabular}{|c|c|c|c|}
\hline \multicolumn{2}{|l|}{ Kiến thức về SKSS trẻ VTN } & Số lượng (n) & Tỷ lệ (\%) \\
\hline \multirow{2}{*}{ Có nghe về SKSS trẻ VTN } & Đạt & 378 & 89,6 \\
\hline & Chưa đạt & 44 & 10,4 \\
\hline \multirow{2}{*}{ Các nội dung về SKSS trẻ VTN } & Đạt & 269 & 63,7 \\
\hline & Chưa đạt & 153 & 36,3 \\
\hline \multirow{2}{*}{ Thay đổi về cơ thể của trẻ ở trẻ VTN } & Đạt & 332 & 78,7 \\
\hline & Chưa đạt & 90 & 21,3 \\
\hline \multirow{2}{*}{ Thay đổi về tâm lí của trẻ ở trẻ VTN } & Đạt & 304 & 72,0 \\
\hline & Chưa đạt & 118 & 28,0 \\
\hline \multirow{2}{*}{$\begin{array}{l}\text { Những bất thường của cơ quan sinh sản trẻ } \\
\text { VTN }\end{array}$} & Đạt & 203 & 48,1 \\
\hline & Chưa đạt & 219 & 51,9 \\
\hline \multirow{2}{*}{ Các bệnh nhiễm khuẩn đường sinh sản } & Đạt & 178 & 42,2 \\
\hline & Chưa đạt & 244 & 57,8 \\
\hline \multirow{2}{*}{$\begin{array}{l}\text { Các biện pháp phòng chống các bệnh nhiễm } \\
\text { khuẩn đường sinh sản }\end{array}$} & Đạt & 247 & 58,5 \\
\hline & Chưa đạt & 175 & 41,5 \\
\hline \multirow{2}{*}{ Tình bạn, tình yêu trẻ VTN } & Đạt & 268 & 63,5 \\
\hline & Chưa đạt & 154 & 36,5 \\
\hline \multirow{2}{*}{$\begin{array}{l}\text { Hậu quả của việc quan hệ tình dục sớm, mang } \\
\text { thai ngoài ý muốn ở trẻ VTN }\end{array}$} & Đạt & 370 & 87,7 \\
\hline & Chưa đạt & 52 & 12,3 \\
\hline
\end{tabular}




\begin{tabular}{|c|c|c|c|}
\hline \multirow{2}{*}{ Tránh mang thai ngoài ý muốn ở trẻ VTN } & Đạt & 282 & 66,8 \\
\hline & Chưa đạt & 140 & 33,2 \\
\hline \multirow{2}{*}{$\begin{array}{l}\text { Biện pháp phòng chống xâm hại, quây rối tình } \\
\text { dục cho trẻ VTN }\end{array}$} & Đạt & 298 & 70,6 \\
\hline & Chưa đạt & 124 & 29,4 \\
\hline \multirow{2}{*}{ Đối tượng cần giáo dục về SKSS trẻ VTN } & Đạt & 383 & 90,8 \\
\hline & Chưa đạt & 39 & 9,2 \\
\hline \multirow{2}{*}{ Nguồn thông tin về SKSS cho trẻ VTN } & Đạt & 253 & 60,0 \\
\hline & Chưa đạt & 169 & 40,0 \\
\hline \multirow{2}{*}{$\begin{array}{c}\text { Đối tượng có trách nhiệm giáo dục SKSS cho } \\
\text { trẻ VTN }\end{array}$} & Đạt & 259 & 61,4 \\
\hline & Chưa đạt & 163 & 38,6 \\
\hline
\end{tabular}

Hơn 70\% các bậc phụ huynh nắm được những nội dung cơ bản trong. Giáo dục sức khoẻ sinh sản. Tuy nhiên, những nội dung liên quan đến bất thường cơ quan sinh sản, bệnh nhiễn khuẩn đường sinh sản, các biện phápp phòng chống nghiễn khuẩn đường sinh sản, tình bạn tình yêu trẻ VTN, tránh mang thai ngoài ý muốn, các nguồn thông tin về SKSS cho trẻ VTN và các đối tượng có trách nhiệm giáo dục SKSS cho trẻ VTN có kiến thức chưa đạt với tỷ lệ từ 33,2\%- 57,8\%.

3.3. Thái độ của cha mẹ học sinh vê vấn đề giáo dục sức khỏe sinh sản trẻ VTN cho con $(n=422)$

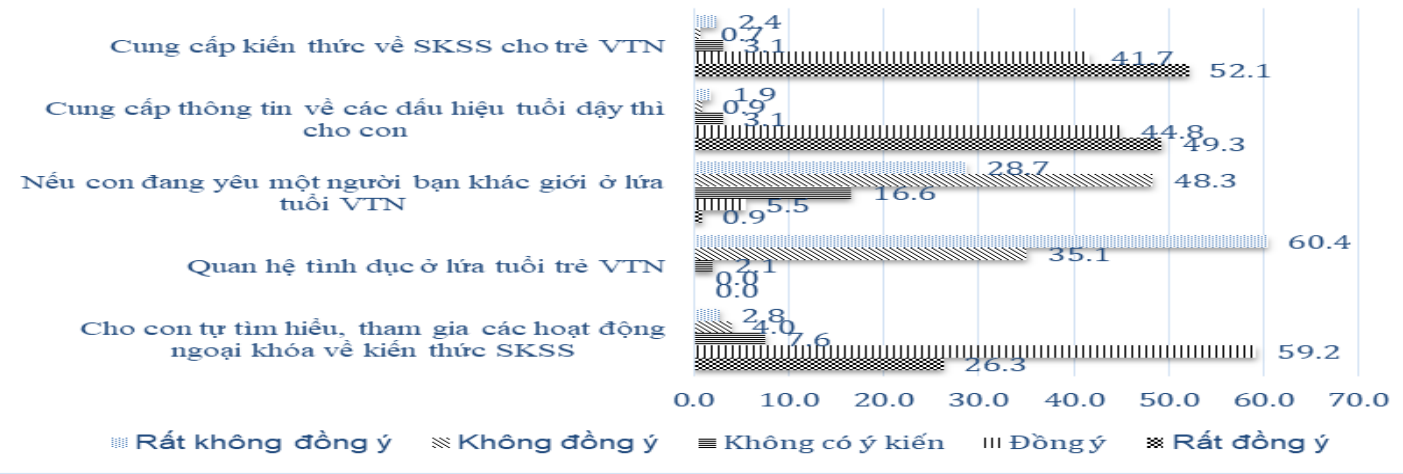

Biểu đồ 1. Thái độ của cha mẹ học sinh đôii với vấn đề giáo dục sức khỏe sinh sản trẻ VTN cho con

Kết quả nghiên cứu thái độ của cha me xung quanh việc giáo dục cho con họ. Trong đó, cha mẹ rất đồng ý cung cấp những nội dung liên quan đến việc cung cấp kiến thức về SKSS, những dấu hiệu tuổi dạy thì của con, cũng như là cho phép con tìm hiểu, tham gia các hoạt động ngoại khoá về kiến thức SKSS. Tuy nhiên, đối với

thái độ liên quan đến tình yêu khác giới và quan hệ tình dịch ở lứa tuổi trẻ VTN, tỷ lệ các phụ huynh có thái độ không đồng ý và rất không đồng ý còn cao, chiếm tỷ lệ từ 77\%-95,4\%.

3.4. Thực hành của cha me học sinh vê vấn đề giáo dục sức khỏe sinh sản trẻ VTN cho con $(\mathrm{n}=422)$

Bảng 4. Thực hành của cha me học sinh đối với giáo dục vân đề sức khỏe sinh sản trẻ VTN cho con

\begin{tabular}{|c|c|c|c|}
\hline \multirow{2}{*}{$\begin{array}{c}\text { Có trò chuyện với } \\
\text { con về SKSSS }\end{array}$} & Thực hành về SKSS trẻ VTN & Số lượng (n) & Tỷ lệ (\%) \\
\cline { 2 - 4 } & Không & 306 & 72,5 \\
\hline \multirow{3}{*}{$\begin{array}{c}\text { Vấn đề trao đổi } \\
\text { nhiều nhất }\end{array}$} & Thay đổi của cơ thể, tâm lý tuổi mới lớn & 116 & 27,5 \\
\cline { 2 - 4 } & Bệnh nhiếm khuâ̂n đường sinh sản & 218 & 71,2 \\
\cline { 2 - 4 } & Tình bạn, tình yêu, tình dục trẻ VTN & 9 & 2,9 \\
\cline { 2 - 4 } & Các biện pháp phòng tránh thai & 9 & 22,9 \\
\hline \multirow{3}{*}{$\begin{array}{c}\text { Khoảng thời gian } \\
\text { trao đổi }\end{array}$} & Lúc ăn cơm cung gia đình/ mua sắm/ xem phim & 115 & 2,9 \\
\cline { 2 - 4 } & Khi con có thắc mắc thì mới trao đối & 152 & 26,9 \\
\cline { 2 - 4 } & Bất cứ khi nào rảnh thì cùng con thảo luận về vấn đề đó & 132 & 23,4 \\
\cline { 2 - 4 } & Khi ở riêng một mình với con & 166 & 29,4 \\
\hline
\end{tabular}


VIETNAM MEDICAL JOURNAL N²2 - DECEMBER - 2021

\begin{tabular}{|c|c|c|c|}
\hline \multirow{3}{*}{$\begin{array}{c}\text { Những khó khan } \\
\text { khi trao đổi với } \\
\text { con về SKSS }\end{array}$} & Không đủ kiến thức & 153 & 50,0 \\
\cline { 2 - 4 } & Rào cản về quan niệm & 119 & 38,9 \\
\cline { 2 - 4 } & Không biết phương pháp & 120 & 39,2 \\
\cline { 2 - 4 } & Không đủ thời gian & 140 & 45,8 \\
\hline \multirow{3}{*}{$\begin{array}{c}\text { Lý do chưa trò } \\
\text { chuyện cùng con }\end{array}$} & Nhạy cảm & 125 & 40,8 \\
\cline { 2 - 4 } & Không nắm rõ kiến thức về SKSS & 61 & 52,6 \\
\cline { 2 - 4 } & Không quan tâm & 93 & 37,1 \\
\cline { 2 - 4 } & Bận rộn & 55 & 47,4 \\
\cline { 2 - 4 } & E ngại vì các vấn đề nhạy cảm & 45 & 38,8 \\
\hline & Con còn nhón & 2 & 1,7 \\
\hline
\end{tabular}

Kết quả cho thấy, có $71,2 \%$ đối tượng có giáo dục con cái về SKSS, chủ yếu về thay đổi về cơ thể và tâm lý tuổi mới lớn, chiếm tỷ lệ $71,2 \%$. Khoảng thời gian các phu huynh trao đổi với con mình tương đối đa dạng. Hầu như các đối tượng tham gia nghiên cứu đều gặp những khó khăn liên quan đến kiến thức, sự nhạy cảm của vấn đề, rào cản về quan niệm, phướng pháp và thời gian. Đối với nhóm chưa từng trò chuyện cùng con, nguyên nhân chủ yếu là do thời gian bận rộn $(77,6 \%)$, và không nắm rõ kiến thức về SKSS $(52,6 \%)$.

\section{BÀN LUÂNN}

4.1. Kiến thức của cha mẹ học sinh về vấn đề giáo dục SKSS trẻ VTN. Nghiên cứu chỉ ra có $58,1 \%$ có kiến thức đạt về SKSS, tương đồng với kết quả nghiên cứu đánh giá kiến thức của cha me liên quan đến sức khoẻ sinh sản của Evelyn Serwaa Adjei (2020) [2] , trong đó, những nội dung cùng được đánh giá trong thang đo là những thay đổi về sinh lý, bệnh lây truyền qua đường tình dục và biện pháp trành thai. Kết quả này lại thấp hơn so với nghiên cứu của Tesfaye Assebe Yadeta (2014) với tỷ lệ là $65,32 \%$ [6]. Sự khác biệt này là do đặc điểm nhân khẩu học - xã hội của đối tượng nghiên cứu, trong đó phương pháp chọn mẫu có sự khác biệt lớn. Ngoài ra môi trường sống là những quận trung tâm gần với các trụ sở chính quyền, trung tâm văn hoá như trong nghiên cứu của Tesfaye Assebe Yadeta có thể là nguyên nhân cho sự khác biệt lớn này.

4.2. Thái độ của cha me học sinh về vấn đề giáo dục SKSS trẻ VTN. Các bậc cha me có thái độ quan tâm đến vấn đề giáo dục sức khỏe sinh sản cho VTN $(52,8 \%)$. Kết quả này cũng thấp hơn kết quả thu được trong nghiên cứu của Tesfaye Assebe Yadeta (2014) là 80,43\% [6]. Những kết quả cụ thể liên quan đến thái độ về SKSS của cha me trong nghiên cứu đã chỉ ra những định kiến nhất định liên quan đến vấn đề này, làm hạn chế thái độ tích của cuả đối tượng tham gia.

4.3. Thực hành của cha me học sinh vê vấn đề giáo dục SKSS trẻ VTN. Cha me có tỷ lệ đat về thực hành là $51,7 \%$. Theo kết quả nghiên cứu của chúng tôi, có $72,5 \%$ cha mẹ có trao đổi với con về vấn đề sức khỏe sinh sản, cao hơn so với nghiên cứu của Tesfaye Assebe Yadeta (2014) với tỷ lệ là $28,76 \%$ [6]điêu này được giải thích bởi sự khác biệt về tý lệ cha mẹ có trò chuyện cùng con liên quan đến những vấn đề SKSS ở quần thể dân cư Viêt Nam và Ethiopia đã có những khác biệt lớn [6]. Tỷ lệ kiến thức và thái độ không cao đã dẫn đến tỷ lệ thực hành thấp. Sư han chế trao đổi của cha me đối với con cái trẻ VTN về chủ đề sức khỏe sinh sản một phần do rào cản về quan niệm, một phần còn $\mathrm{e}$ ngại vì cho rằng đây là điều tế nhị, nhạy cảm và phần khác do khó khăn trong việc truyền đạt, bên cạnh đó, một bộ phân cha me cảm thấy không đủ kiến thức để giải thích về chủ đề này cho VTN.

\section{KẾT LUÂN}

Nghiên cứu được tiến hành trên 422 cha me học sinh tại 4 trường trung học cơ sở trên địa bàn tỉnh Thừa Thiên Huế cho thấy có $58,1 \%$ cha mẹ đạt kiến thức chung, 52,8\% cha me đạt thái đồ và $51,7 \%$ cha me có thực hành đạt về vấn đề sức khỏe sinh sản trẻ VTN.

\section{TÀI LIÊU THAM KHẢO}

1. Bô Y Tế (2021), Kế hoạch hàng đông Quốc gia về chăm sóc sức khoẻ sinh sản, tấp trung vào chăm sóc sức khoẻ bà mê, trẻ sơ sinh và trẻ nhỏ giai đoạn 2021-2025, Bộ Y Tế, chủ biên.

2. Evelyn Serwaa Adjei và Kennedy Ameyaw Baah (2020), "Assessing the Impact of Parents' Adolescent Reproductive and Sexual Health Knowledge on Sexual Health Education by Parents in the Asutifi (North and South) Districts of Ghana", International Journal of Scientific Research and Management. 8(09), tr. 1626-1633.

3. A. J. Huebner và L. W. Howell (2003), "Examining the relationship between adolescent 
sexual risk-taking and perceptions of monitoring, communication, and parenting styles", J Adolesc Health. 33(2), tr. 71-8.

4. K. Phongluxa và các cộng sự. (2020), "Factors influencing sexual and reproductive health among adolescents in Lao PDR", Glob Health Action. 13(sup2), tr. 1791426.

5. Ann M. Starrs và các cộng sự. (2018), "Accelerate progress-sexual and reproductive health and rights for all: report of the GuttmacherLancet Commission", The Lancet. 391(10140), tr.
2642-2692.

6. T. A. Yadeta, H. K. Bedane và A. K. Tura (2014), "Factors affecting parent-adolescent discussion on reproductive health issues in Harar, eastern Ethiopia: a cross-sectional study", J Environ Public Health. 2014, tr. 102579.

7. Amsale Cherie Yemane Berhanie (2015), "Assessment of Parenting Practices and Styles and Adolescent Sexual Behavior among High School Adolescents in Addis Ababa, Ethiopia", Journal of AIDS \& Clinical Research. 06(02).

\section{NGHIÊN CỨU SỰ THAY ĐỔI AFP, AFP-L3, PIVKA-II TRƯớC VÀ SAU ĐIỀU TRI BỆNH NHÂN UNG THƯ BIỂU MÔ TẾ BÀO GAN}

\section{TÓM TẮT}

Mục tiêu: Mục đích của nghiên cứu đánh giá vai trò của bô ba marker AFP, AFP-L3, PIVKA-II trong việc đánh giá điều trị của bệnh nhân ung thư biểu mô tế bào gan. Đối tượng và phương pháp: Tổng số nghiên cứu trên 29 bệnh nhân ung thư biểu mô tể bào gan tham gia nghiên cứu được đánh giá đặc điểm lâm sàng, cận lâm sàng và sự đáp ứng của AFP, AFP-L3, PIVKA-II sau điều trị 1 tháng và 3 tháng. Kết quả: Trong 29 bệnh nhân, tuổi trung bình của bệnh nhân là $60,5 \pm 10,1$ tuổi. Các yếu tố nguy cơ của ung thư gan là viêm gan virus $B, C$ và rượu. Kết hợp 3 marker AFP AFP-L3 và PIVKA-II giúp làm tăng độ nhạy trong chẩn đoán HCC so với việc sử dụng đơn độc từng marker. Sau điều trị 1 tháng và 3 tháng bằng phương pháp TACE hoăc RFA ở bênh nhân HCC, nồng đồ huyết thanh trung bình của các marker AFP, AFP-L3 và PIVKA-II giảm so với trước điều trị Kết luận: Kết hợp 3 marker AFP, AFP-L3 và PIVKA-II giúp tăng khả năng dư báo đáp ứng về chẩn đoán hình ảnh sau điều trị bệnh nhân ung thư biểu mô tế bào gan so với việc sử dưng đơn đôc từng marker.

Tư khóa: AFP, AFP-L3 và PIVKA-II, ung thư biểu mô tế bào gan.

\section{SUMMARY \\ RESEARCH ON CHANGES OF AFP, AFP-L3, PIVKA-II BEFORE AND AFTER TREATMENT OF HEPATOCELLULAR CARCINOMA}

Objective: The purpose of this study is to evaluate the role of three markers AFP, AFP-L3, PIVKA-II in evaluating the treatment of patients with hepatocellular carcinoma. Subjects and methods: A total 29 patients with hepatocellular carcinoma participating in the study evaluated the clinical,

${ }^{1}$ Trung tâm tiêu hóa gan mật bệnh viện Bạch mai Bệnh viện đa khoa Hà Đông

Chịu trách nhiệm chính: Nguyễn Công Long

Email: nguyenconglongbvbm@gmail.com

Ngày nhận bài: 13.9.2021

Ngày phản biện khoa học: 10.11.2021

Ngày duyệt bài: 17.11.2021

\section{Nguyễn Công Long1, Nguyễn Bá Vượng}

laboratory and response characteristics of AFP, AFPL3, PIVKA-II after 1 month of treatment and 3 months. Results: In 29 patients, the mean age of patients was $60.5 \pm 10.1$ years. The risk factors for liver cancer are hepatitis $B$ and $C$ viruses and alcohol. The combination of three markers AFP, AFP-L3 and PIVKA-II increases the sensitivity in the diagnosis of HCC compared with the use of each marker alone. After 1 month and 3 months of treatment with TACE or RFA in HCC patients, mean serum levels of AFP, AFP-L3 and PIVKA-II markers decreased compared with before treatment. Conclusions: The combination of three markers AFP, AFP-L3 and PIVKAII increases the predictive power of imaging response after treatment of HCC patients compared with the use of each marker alone.

Keywords. AFP, AFP-L3, PIVKA-II and Hepatocellular carcinoma.

\section{I. ĐĂT VẤN ĐỀ}

Ung thư biểu mô tế bào gan là một trong những loại ung thư phổ biến nhất trên thế giới, là loại ung thư có số người mắc đứng thứ 5 ở nam giới và đứng thứ 7 ở nữ giới, nó cũng là một trong ba loại ung thư gây tử vong nhiều nhấttrên toàn thể giới $[1,2]$. Cùng với chẩn đoán hình ảnh, các marker khối u có một vai trò quan trọng trong việc chẩn đoán cũng như theo dõi kết quả điều trị và theo dõi sự tái phát của ung thư biểu mô tế bào gan. Tuy nhiên các nghiên cứu gần đây cho thấy AFP chỉ tăng trong khoảng $60 \%$ các trường hợp HCC và trên thực tế lâm sàngcó nhiều bệnh nhân không đáp ứng với điều trịnhưng nồng độ AFP trong huyết thanhlại giảm một cách rõ rệt sau điều trị. Đó chính là những hạn chế của AFP trong việc chẩn đoán và theo dối sau điều trị HCC.

Trong khi đó AFP-L3 và PIVKA-II là những marker khối u được phát hiện và ứng dụng sau AFP, giúp tăng khả năng chẩn đoán HCC. Trên thế giới đã có nhiều công trình nghiên cứu khẳng 